\title{
Serum homocysteine and vitamin B12 levels in women with gestational diabetes mellitus
}

\author{
Sandra Radzicka ${ }^{1}$, Katarzyna Ziolkowska ${ }^{2}$, Mikolaj Piotr Zaborowski ${ }^{3}$, \\ Jacek Brazert ${ }^{1}$, Marek Pietryga ${ }^{1}$ \\ ${ }^{1}$ Department of Obstetrics and Women's Diseases, University of Medical Sciences, Poznan, Poland \\ ${ }^{2}$ Chair and Department of Laboratory Diagnostics, Poznan University of Medical Sciences, Poznan, Poland \\ ${ }^{3}$ Department of Gynecology, Obstetrics and Gynecologic Oncology, Division of Gynecologic Oncology, \\ Poznań University of Medical Sciences, Poznań, Poland
}

\begin{abstract}
Objectives: Gestational diabetes mellitus (GDM) is described as a glucose intolerance of variable severity which begun or was firstly recognized during gravidity. Two major metabolic disorders, insulin resistance and $\beta$-cell dysfunction, currently play major role in pathogenesis of GDM. Our intention was to investigate total serum homocysteine and vitamin B12 levels in pregnant women with GDM and non-diabetic gravid women.

Material and methods: Serum homocysteine and vitamin B12 levels were prospectively measured in a total of 79 pregnant women, 60 of whom were diagnosed with GDM, and 19 of whom were healthy controls. Serum homocysteine levels were analyzed by ELISA. Vitamin B12 concentrations were determined by chemiluminescent immunoassay, and lipids were determined enzymatically.

Results: GDM and control groups did not differ in terms of the serum homocysteine levels (median $7.24 \mathrm{vs} 7.97 \mathrm{umol} / \mathrm{L}$, respectively, $p=0.15)$. Nor did we find any association between serum homocysteine levels and $B M I(r=0.06, p=0.55$, respectively). There was no correlation between serum homocysteine and fasting serum glucose $(r=0.3, p=0.8$, respectively). There was no relationship between serum homocysteine concentrations and glycosylated hemoglobin (HgbA1c) levels $(r=0.06, p=0.67$, respectively). Serum vitamin B12 concentrations did not differ between the GDM and control groups (median $286 \mathrm{vs} 262 \mathrm{pg} / \mathrm{mL}$, respectively, $\mathrm{p}=0.17$ ). We found that levels of Vitamin B12 correlated inversely with fasting serum glucose concentrations $(r=-0.44, p=0.0009)$. Vitamin B12 concentrations increased along with $L D L(r=0.27, p=0.043)$ and $\mathrm{HDL}(r=0.38, p=0.004)$ levels, however were inversely correlated with serum triglycerides $(r=-0.34, p=0.009)$.

Conclusions: GDM patients with low Vitamin B12 values tend to have higher fasting serum glucose and altered lipid profiles (high triglycerides, low HDL and LDL). In women with GDM, serum homocysteine levels are not associated with $\mathrm{HbA1c}$ level, fasting glycemia, or BMI.
\end{abstract}

Key words: gestational diabetes mellitus; GDM; adipocytokines; serum homocysteine; Vitamin B12; pregnancy; glucose intolerance

Ginekologia Polska 2019; 90, 7: 381-387

\section{INTRODUCTION}

Gestational diabetes mellitus (GDM) is a frequent complaint that affects relatively $7-14 \%$ of pregnancies. GDM is specified as any degree of glucose intolerance with commencement or first diagnosis during gravidity [1, 2]. The prevalence of GDM depends to a high degree on the ethnicity of the patient and on the diagnostic criteria used [3]. Although adverse lifestyle factors (overnutrition and physical inactivity) contribute to obesity, a significant number of trials connect early-life nutrient imbalance with the development of metabolic disorders in childhood and early adulthood. Maternal obesity is characterised by the existence of an enormous amount of adipose tissue (AT) and negative effects on maternal wellbeing and the developing fetus, leading to cardiometabolic syndrome in children later in life [4].

In humans, homocysteine is formed during the methionine metabolic cycle. The re-methylation of homocysteine 
would not be possible without the enzyme methionine synthase (MS) with which vitamin B12 is a co-factor and methyltetrahydrofolate (methylTHF) a substrate. This process is indirectly controlled by the activity of the enzyme methylenetetrahydrofolate reductase (MTHFR). Disturbances in the metabolism of homocysteine caused by the deficiency of co-factors or by some genetic enzyme defect, lead to cellular accumulation of homocysteine which consequently elevates plasma homocysteine levels [5]. Compared with concentrations in nonpregnant women, serum homocysteine has been found to reduce during each trimester of gravidity (due to either a physiological answer to the pregnancy, an increase in estrogen, hemodilution from an elevated plasma volume, or enlarged demand for methionine by both women and fetus) [6]. Elevated homocysteine concentrations during pregnancy are associated with an increased incidence of spontaneous abortion, intrauterine growth restriction, placental infarction, neural tubes defects and pre-eclampsia. Some researchers showed that hyperhomocysteinemia was associated with early pregnancy losses and adverse pregnancy outcomes. [7-9]. When it comes to studies about plasma homocysteine levels and glucose tolerance in both diabetic and non-diabetic gravid women, it has also been shown that there is an association between hyperhomocysteinemia and insulin resistance.

Vitamin B12 deficiency in pregnant women is increasingly popular, and in many studies there has been shown association with higher body mass index (BMI) [10, 11], as well as with insulin resistance (IR), gestational diabetes (GDM), and type 2 diabetes (T2D) in future $[12,13]$.

B12 plays crucial role in the synthesis of methionine, the precursor of S-adenosyl-methionine (SAM), which is a major methyl donor for DNA methylation $[13,14]$.

\section{MATERIAL AND METHODS}

Based on these premises, we studied potential relationship between serum homocysteine and B12 levels in pregnant diagnosed with gestational diabetes mellitus compared with those with normal glucose tolerance. Our analysis was performed in the Department of Obstetrics and Women's Diseases of the Poznan University of Medical Sciences between August 2017 and July 2018. Research ethics approval was obtained before we begun the study and the informed consent was obtained in writing from all participating women. Subjects were qualified for the study if they did not smoke nor took any medication for at least 3 months before recruitment, did not report any vitamin deficiency or significant diseases, and had no history of cardiovascular disease or previous medical history of diabetes mellitus. Women in multiple pregnancies were debarred from the study.

The study population included 79 gravid women, 60 of whom were diagnosed with gestational diabetes and 19 of whom were healthy controls. In our department, we generaly screen our patients between 24 and 28 weeks of gestation unless they have any of the risk factors of obesity, insulin resistance, a family history of any glucose intolerance, or have given birth to a macrosomic baby. The diagnosis of our subjects' gestational diabetes mellitus was based upon the International Association of Diabetes and Pregnancy Study Group (IADPSG) criteria [15, 16]. Body mass indices (BMIs) of the study population were calculated at first visit in pregnancy.

\section{Statistical analysis}

R programming language (version 3.4.1) was used for statistical analysis. The distribution was determined with the Shapiro test. In case of normal distribution, the t-Student test (two-group comparison) or ANOVA (multigroup comparison) were applied. The sets with non-normal distribution were compared with the Mann-Whitney (two-group comparison) or the Kruskal-Wallis test (multiple groups comaprison). Linear relationships between parameters were determined by Pearson and Spearman correlation coeffcients for normal and non-normal data distribution, respectively. The $p$ values below 0.05 were considered significant. $R$ packages (ggplot2, ggpubr) were used to generate plots (geom_boxplot() function) and add labels with applied statistics and $p$ values (stat_compare_means() function). Data representing individual patients were visualised as dots in the boxplots.

\section{Blood samples}

We gathered $9 \mathrm{~mL}$ of blood for freezing and later testing. Specimens were immediately kept at 4 degrees Celsius and processed within $4 \mathrm{~h}$ to avoid cell lysis. Blood fractionation was carried out centrifuge at $2500 \mathrm{xg}$ for $10 \mathrm{~min}$, and $3-4 \mathrm{~mL}$ of the blood serum's supernatant was removed and stored at -80 degrees Celsius. For homocysteine analysis, samples were determined by an enzymatic test using Cobas c501 analyzer. Vitamin B12 was analysed using electrochemiluminescent immunoassay (ECLIA) with a Cobas e601 analyser (Roche Diagnostics Poland). The inter assay coefficient of variation was $2 \%$ for plasma homocysteine, and for values above the reference range, $1.4-2 \%$. However, the coefficient of variation for TB12 was 3.2-4.3\%, and for values above the reference range, $3.8 \%$. The reference range for vitamin B12 was 197-771 pg/mL (2.5-97.5 percentile). On the other hand, the reference range for homocysteine was 12-15 umol/L (adults 15-65 years old). Serum glucose, cholesterol, triglycerides, and HDL cholesterol were determined using a Cobas c501 auto analyser (Roche Diagnostics Poland). Using enzymatic colourimetric assay, insulin was measured by the electrochemiluminescence method with a Cobas e601 analyser (Roche Diagnostics Poland). LDL cholesterol was calculated using the Friedewald formula. 


\begin{tabular}{|c|c|c|}
\hline \multirow{2}{*}{ Parameter } & GDM & Control \\
\hline & Group $(n=60)$ & Group (n= 19) \\
\hline Age [years] & $32.27+/-4.5$ & $33.73+/-5.0$ \\
\hline Weight [kg] & $76.58+/-14.6$ & $73.73+/-11.27$ \\
\hline Height [m] & $1.65+/-0.06$ & $1.62+/-0.06$ \\
\hline BMI [kg/m2] & 27.59 & 26.98 \\
\hline Gestational age [weeks] & $33.26+/-5.54$ & $34.88+/-5.66$ \\
\hline \multicolumn{3}{|l|}{$\begin{array}{l}\text { Number of previous } \\
\text { pregnancies: }\end{array}$} \\
\hline 1st pregnancy & $26(43.33 \%)$ & $7(36.84 \%)$ \\
\hline 2nd pregnancy & $20(33.33 \%)$ & $8(42.11 \%)$ \\
\hline 3rd pregnancy & $11(18.33 \%)$ & $2(10.53 \%)$ \\
\hline 4rd pregnancy & $3(5.0 \%)$ & $2(10.53 \%)$ \\
\hline Homocysteine [umol/L] & $7.41+/-2.61$ & $8.02+/-2.27$ \\
\hline \multirow{2}{*}{ Vitamin B12 [pg/mL] } & $287.45+/-111.44$ & $246.30+/-101.69$ \\
\hline & $(215.0-321.30)^{*}$ & $(160.30-309.20)^{*}$ \\
\hline $\begin{array}{l}\text { Systolic Blood Pressure- } \\
\text { SBP [mmHg] }\end{array}$ & $108.33+/-8.87$ & $113.42+/-10.14$ \\
\hline $\begin{array}{l}\text { Diastolic Blood Pressure- } \\
\text { DBP [mmHg] }\end{array}$ & $68.25+/-7.74$ & $70.78+/-7.68$ \\
\hline Previous GDM & $3(5.08 \%)$ & $1(5.2 \%)$ \\
\hline $\begin{array}{l}\text { Gestational Age at Birth } \\
\text { [weeks] }\end{array}$ & $38.89+/-1.59$ & $37.53+/-2.87$ \\
\hline Birth weight [g] & $3385.00+/-492.64$ & $3421.42+/-564.18$ \\
\hline \multicolumn{3}{|l|}{ Gender: } \\
\hline Male & $31.58 \%$ & $50 \%$ \\
\hline Female & $68.42 \%$ & $50 \%$ \\
\hline
\end{tabular}

* - median, interquartile range

\section{RESULTS}

The age of patients in our study ranged from 22 to 43 years old. The mean age of the patients with gestational diabetes mellitus (GDM) was 32, whereas in the control (Ctrl) group it was 33 years. The clinical characteristics of the patients are shown in Table 1. There was no difference in body mass index (BMI) between the groups. The mean gestational age of diabetic patients ( 33 weeks) was comparable to that of the healthy controls (34 weeks). The clinical characteristics of the subgroups based on BMI intervals is presented in Table 2.

The GDM and Ctrl groups did not differ in terms of serum homocysteine levels (median 7.24 vs 7.97 umol/L, respectively, $p=0.15$, Wilcoxon test, Figure $1 \mathrm{~A}$ ). Serum homocysteine levels did not correlate with BMI (Pearson correlation, $r=0.06, p=0.55$, Figure $1 B$ ) and nor did they differ across BMI intervals ( $p=0.95$, Kruskal-Wallis test, Figure 1C). Next, we tested whether serum homocysteine levels could reflect
Table 2. The clinical characteristics of subgroups depending on BMI intervals

\begin{tabular}{|c|c|c|c|c|c|}
\hline BMI & $<20$ & $20-24.9$ & $25-29.9$ & $30-34.9$ & $>35$ \\
\hline $\begin{array}{l}\text { Number of } \\
\text { patients }\end{array}$ & 2.00 & 14.00 & 17.00 & 19.00 & 6.00 \\
\hline $\begin{array}{l}\text { Mean body } \\
\text { mass [kg] }\end{array}$ & 46.5 & 60.84 & 78.00 & 84.00 & 95.83 \\
\hline $\begin{array}{l}\text { Homocysteine } \\
\text { [umol/L] }\end{array}$ & 6.63 & 7.35 & 7.18 & 7.41 & 7.35 \\
\hline $\mathrm{B} 12[\mathrm{pg} / \mathrm{mL}]$ & 544.15 & 292.52 & 289.54 & 253.18 & 269.32 \\
\hline $\begin{array}{l}\text { Mean glycemia } \\
{[\mathrm{mg} / \mathrm{dL}]}\end{array}$ & 92.5 & 103.5 & 104.38 & 107.21 & 102.16 \\
\hline $\mathrm{HbA} 1 \mathrm{c}[\mathrm{mmol} / \mathrm{L}]$ & 4.5 & 4.84 & 5.11 & 5.24 & 5.24 \\
\hline $\begin{array}{l}\text { Fasting serum } \\
\text { glucose }[\mathrm{mg} / \mathrm{dL}]\end{array}$ & 70 & 84 & 92.88 & 92.05 & 91.66 \\
\hline $\begin{array}{l}\text { Total } \\
\text { Cholesterol } \\
\text { [mg/dL] }\end{array}$ & 299.5 & 254.22 & 256.06 & 219.58 & 209.08 \\
\hline $\mathrm{HDL}[\mathrm{mg} / \mathrm{dL}]$ & 82.45 & 212.13 & 76.02 & 70.35 & 69.72 \\
\hline LDL [mg/dL] & 179.65 & 122.3 & 127 & 95.40 & 94.06 \\
\hline TAG [mg/dL] & 187.05 & 212.14 & 272.71 & 237.34 & 226.42 \\
\hline Delivery at term & 1 & 8 & 10 & 11 & 4 \\
\hline Cesarean Section & 0 & 6 & 7 & 8 & 4 \\
\hline $\begin{array}{l}\text { Fetal weight at } \\
\text { term }[\mathrm{g}]\end{array}$ & 3263 & 3459 & 3521 & 3341 & 3557 \\
\hline
\end{tabular}

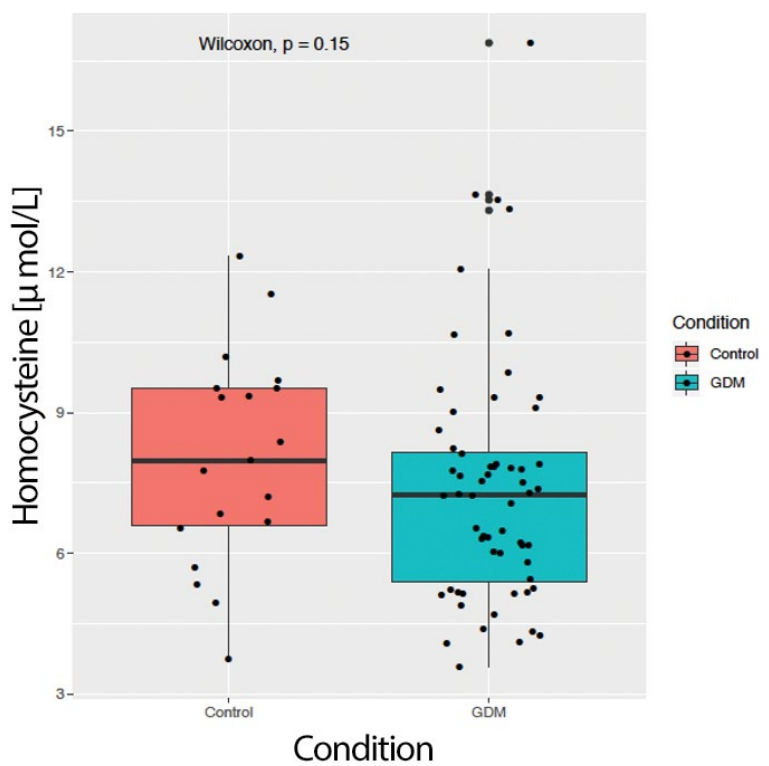

Figure 1A. Serum homocysteine levels in patients with GDM and in Ctrl group

metabolic abnormalities in GDM patients. However, there was no association between serum homocysteine and fasting serum glucose (Pearson correlation, $r=0.03, p=0.8$, Figure 1D). Similarly, there was no correlation between the serum homocysteine concentration and the glycosylated 


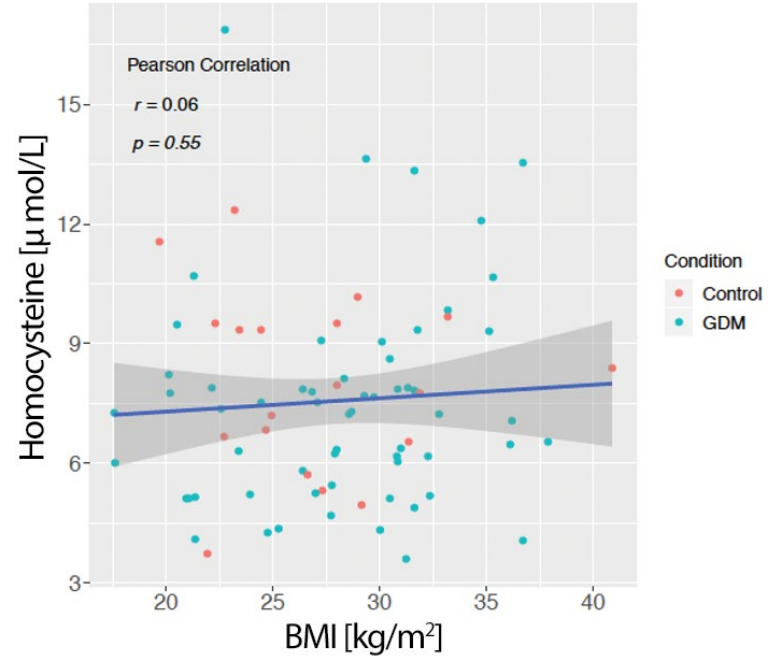

Figure 1B. Serum homocysteine levels and BMI in GDM and Ctrl group

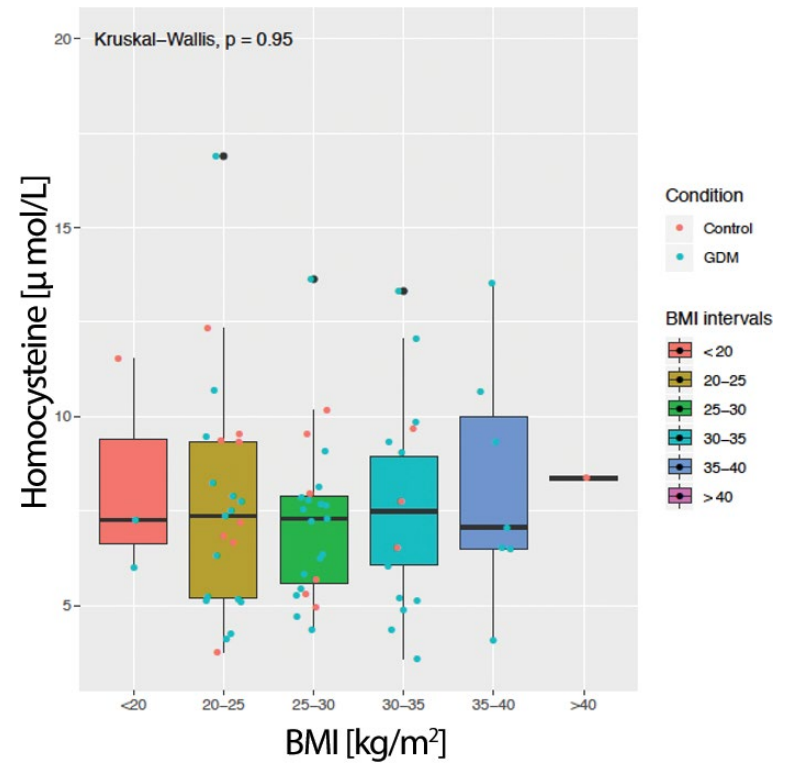

Figure 1D. Serum homocysteine and fasting serum glucose in GDM and $\mathrm{Ctrl}$ group

hemoglobin (HgbA1c) level (Pearson correlation, $r=0.06$, $p=0.67$, Figure $1 E)$.

Serum vitamin B12 did not differ between the GDM and Ctrl groups (median 286 vs $262 \mathrm{pg} / \mathrm{mL}$, respectively, $\mathrm{p}=0.17$, Wilcoxon test, Figure $2 \mathrm{~A}$ ). Nor was serum vitamin $\mathrm{B} 12$ associated with BMI (Pearson correlation, $r=-0.2, p=0.08$, Figure $2 B$ ), and it did not differ across BMl intervals ( $p=0.74$, Kruskal-Wallis test, Figure $2 \mathrm{C}$ ). Next, we analyzed whether vitamin B12 levels were in any relationship to metabolic disturbances within the GDM group. We found that with increasing levels of Vitamin B12, fasting serum glucose concentrations were lower (Pearson correlation, $r=-0.44$, $p=0.0009$, Figure $3 \mathrm{~A}$ ). Correspondingly, we determined that

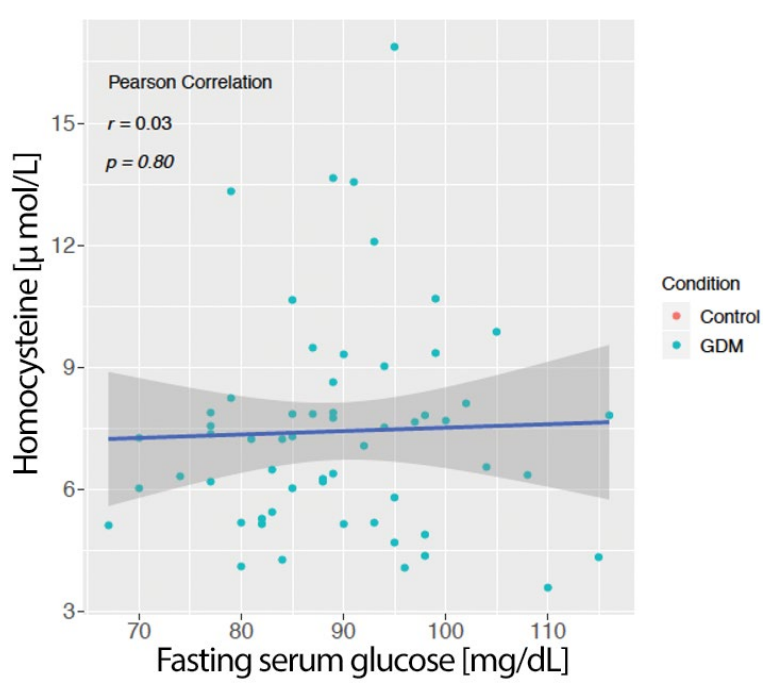

Figure 1C. Serum homocysteine levels and fasting serum glucose in GDM and Ctrl group

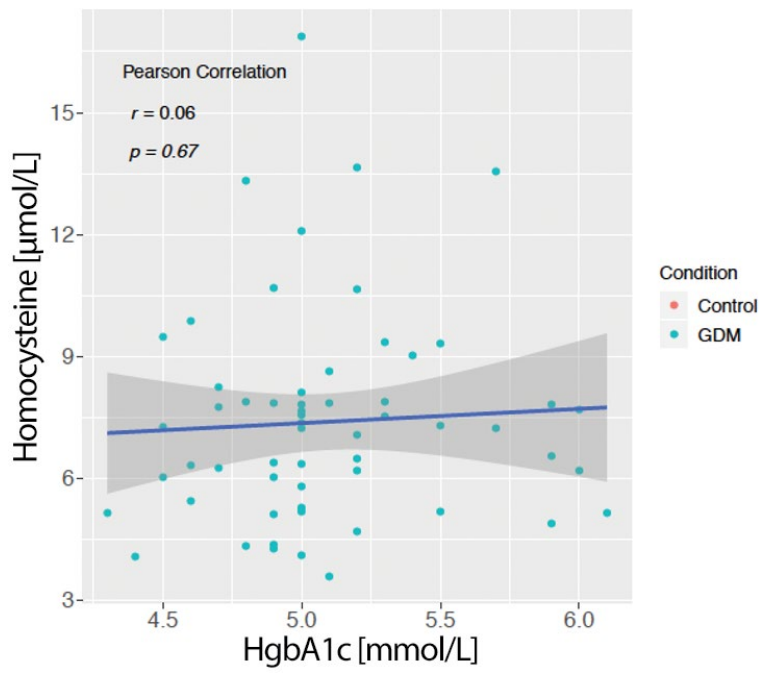

Figure 1E. Serum homocysteine concentration and the glycosylated hemoglobin ( $\mathrm{HgbA} 1 \mathrm{c})$ in GDM and $\mathrm{Ctrl}$ group

HgbA1c increased in relation to decreasing levels of Vitamin B12 (Pearson correlation, $r=-0.36, p=0.006$, Figure 3B). We demonstrated that the Vitamin B12 level was also associated with the lipid profile in patients with GDM. Vitamin B12 concentrations increased together with levels of both LDL (Pearson correlation, $r=0.27, p=0.043$, Figure $4 A$ ) and HDL (Pearson correlation, $r=0.38, p=0.004$, Figure 4B). Serum triglycerides were more likely to be elevated in GDM patients with lower vitamin B12 concentrations (Pearson correlation, $r=-0.34, p=0.009$, Figure $4 C$ ).

\section{DISCUSSION}

Gestational diabetes mellitus is one of the most frequent metabolic disorders complicating pregnancy. The pathophysiology of GDM and type 2 diabetes involves abnormal 


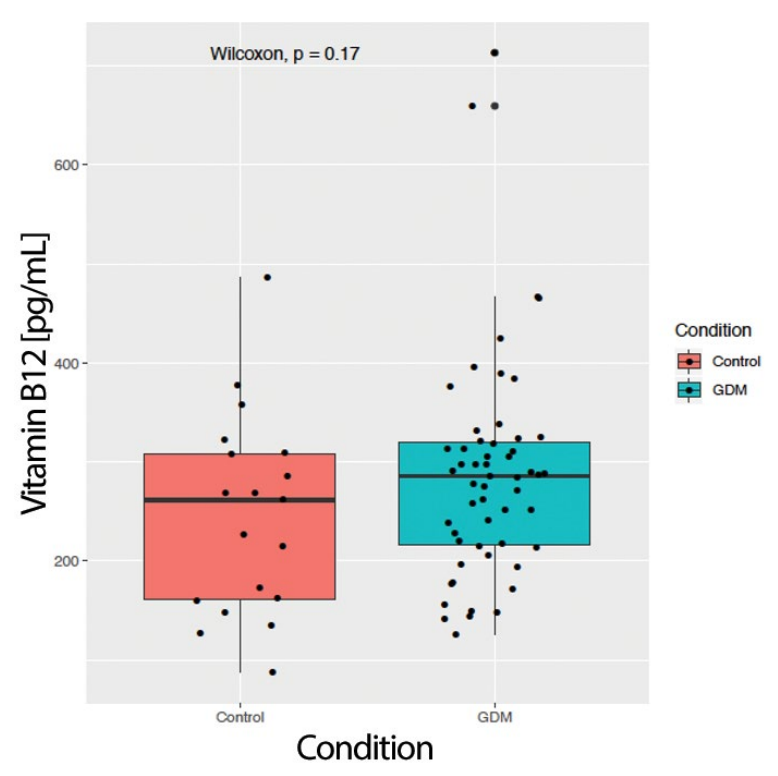

Figure 2A. Serum vitamin B12 in patients with GDM and Ctrl group

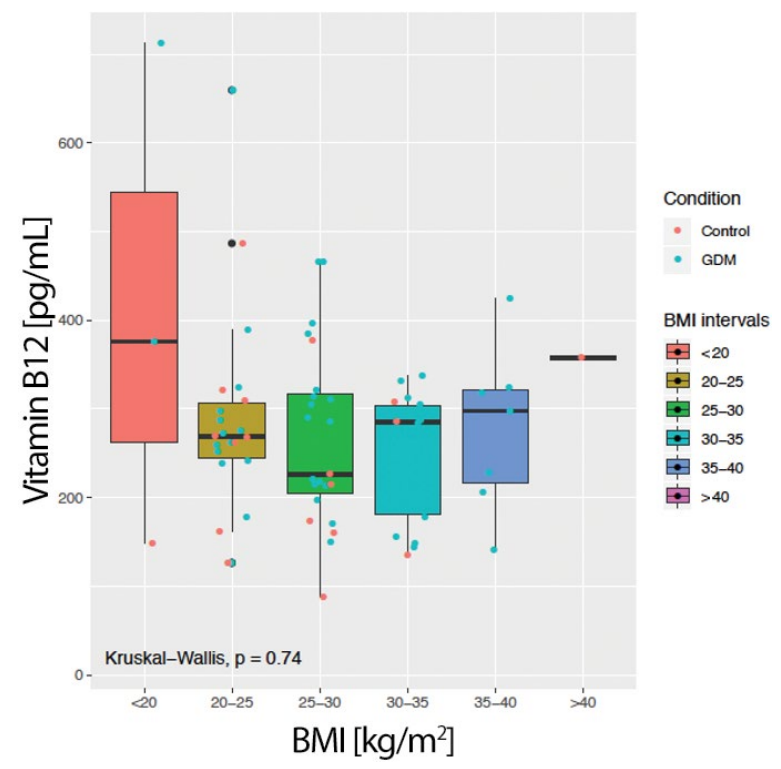

Figure 2C. Serum vitamin B12 and BMI intervals in GDM and Ctrl group

pancreatic insulin release and insulin resistance. The inflammatory markers, metabolic abnormalities and endothelial dysfunctions in GDM can make the pregnant woman suffering from this pathology and her developing fetus much more prone to cardiovascular diseases [17].

One of the factors responsible for this condition is the level of homocysteine. It is proved that acute and chronic exposure to homocysteine shows adverse effects on b-cell metabolism and insulin secretion [18]. Homocysteine levels are influenced by factors, such as age, gender, duration of diabetes, body mass index, nicotine addiction, kidney

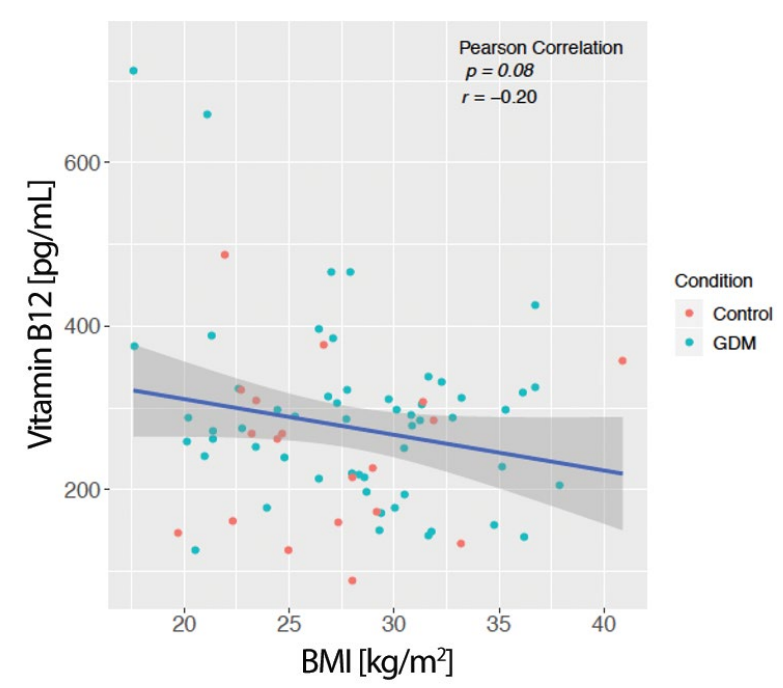

Figure 2B. Serum vitamin B12 levels and BMI in GDM and Ctrl group

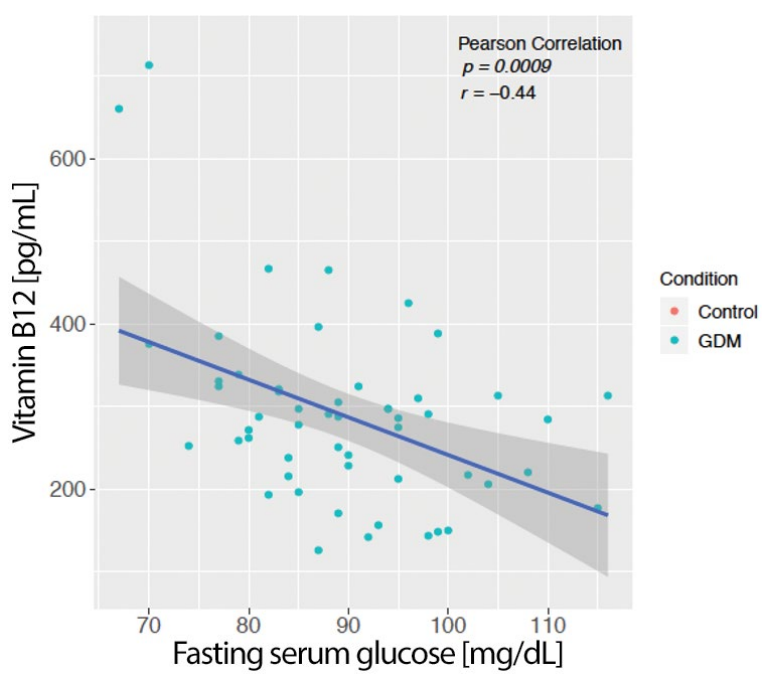

Figure 3A. Serum vitamin B12 and fasting serum glucose concentrations in GDM and Ctrl group

failure, vitamin status and blood pressure, but also by environmental and genetic factors.

In the meta-analysis of Gong et al., serum homocysteine concentrations were higher among women with GDM than among the controls. The evidence was more consistent among women in the second trimester and for women older than 30 years of age. As a result of physiological decreases in albumin during pregnancy, as well as in association with folic acid supplementation, the serum concentrations of homocysteine decrease during pregnancy $[19,20]$. Surprisingly, in our study, we did not find significant differences in those results between the GDM and control groups. The minimum value of homocysteine in our GDM group was 3.59, while the maximum was 16.87 . In the control group, however, the minimum value was 3.75 and the maximum value was 


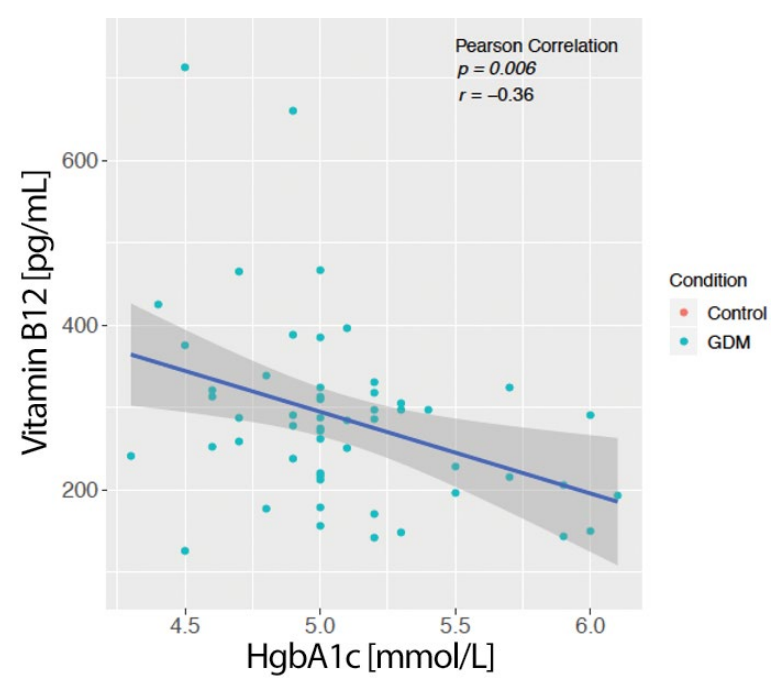

Figure 3B. Serum vitamin B12 concentration and the glycosylated hemoglobin ( $\mathrm{HgbA} 1 \mathrm{c})$ in GDM and Ctrl group

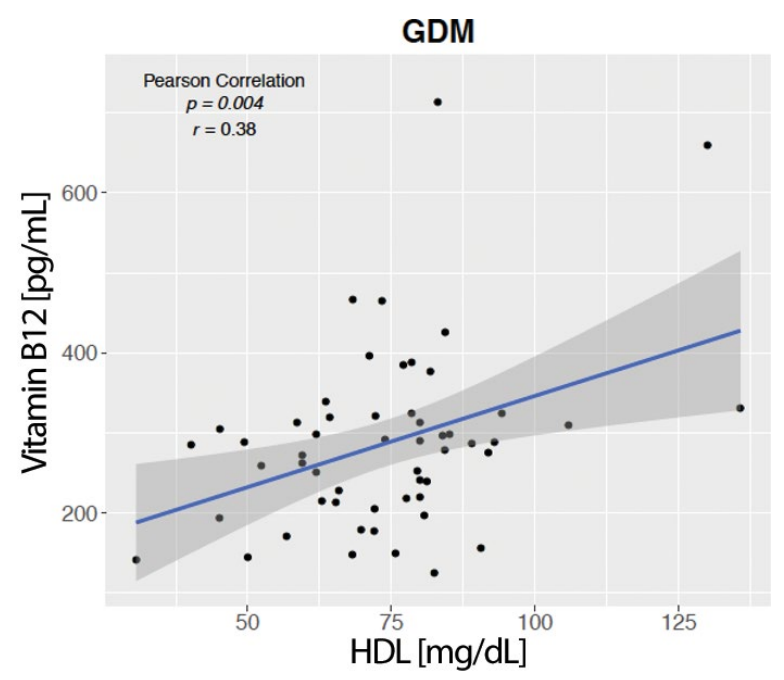

Figure 4B. Correlation between serum vitamin B12 concentration and HDL levels in GDM group

12.34. The small differences between the two groups probably result from the small population of the control group.

It has been proposed that B-vitamins may play crucial role in the pathogenesis of glucose intolerance because of their ability to regulate homocysteine synthesis [21]. Results of recent studies on concentrations of vitamin B12 and its influence on the occurence of gestational diabetes are inconsistent. In the Krishnaveni et al. [22] and Lai et al. [23] studies, it was shown that in a subpopulation of South Asian women, those with vitamin B12 deficiency were much more likely to develop GDM or type 2 diabetes mellitus (T2DM) over the course of a 5 -year follow up period. Similar results of lower vitamin B12 concentrations among pregnant women diabetes in comparison with healthy controls, were pre-

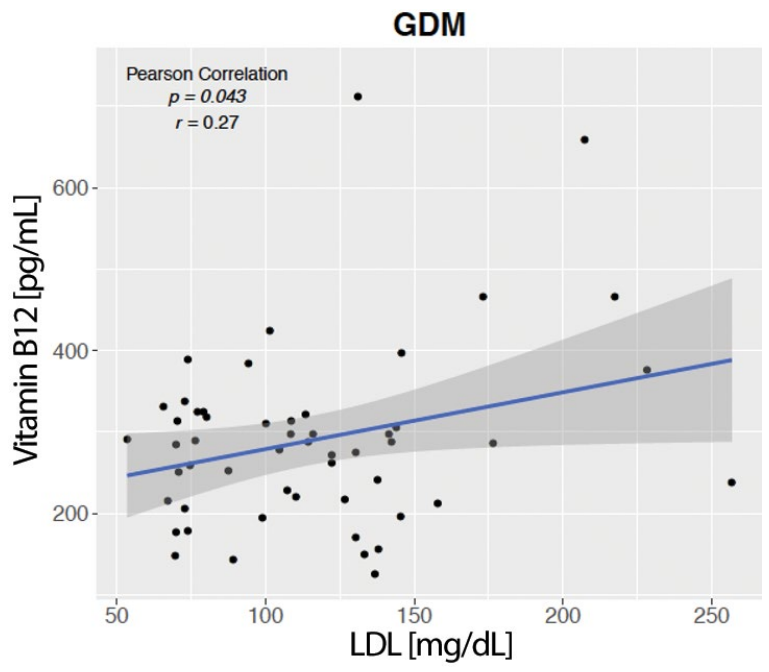

Figure 4A. Correlation between serum vitamin B12 concentration and LDL levels in GDM group

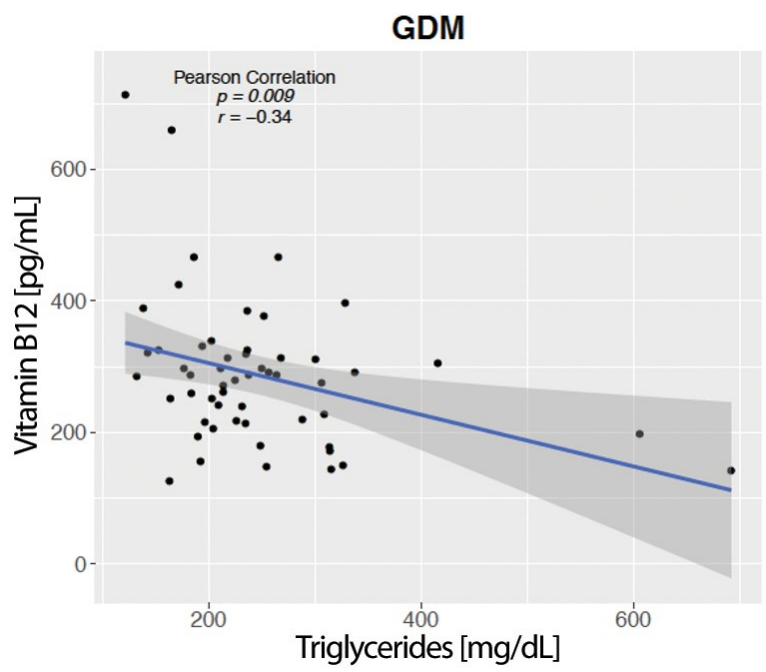

Figure 4C. Correlation between serum vitamin B12 concentration and HDL levels in GDM group

sented in Seghieri's study [24]. However, there are several European studies which did not show differences in folates and vitamin B12 concentrations between women with GDM and those in the control groups [25-27, 12].

\section{CONCLUSIONS}

So far there has been conducted much research on maternal carbohydrates and fats intake and its relation to the risk of developing GDM. It has been suggested that group $B$ vitamins may play role in the pathogenesis of glucose intolerance thank to their ability to regulate synthesis of homocysteine. In other words, vitamin B12 deficiency in pregnancy is related with a higher risk of GDM and type 2 diabetes mellitus. In women with GDM, we did not find 
any correlation between serum homocysteine levels and $\mathrm{HbA1c}$, fasting glycemia or BMI. Conversely, vitamin B12 values are inversely associated with glycemic status and lipid profiles. We concluded that the better the glycemic status of pregnant women with diabetes, the higher the concentration of vitamin B12. We agree that in future, large prospective cohort studies are needed to verify this finding and to evaluate the potential predictive role of these parameters for gestational diabetes mellitus.

\section{REFERENCES}

1. Hunt KJ, Schuller KL. The increasing prevalence of diabetes in pregnancy. Obstet Gynecol Clin North Am. 2007; 34(2): 173-99, vii, doi: 10.1016/j. ogc.2007.03.002, indexed in Pubmed: 17572266.

2. Diagnosis and Classification of Diabetes Mellitus. Diabetes Care. 2009; 33(Supplement_1): S62-S69, doi: 10.2337/dc10-s062.

3. Koning $\mathrm{SH}$, Hoogenberg $\mathrm{K}$, Lutgers $\mathrm{HL}$, et al. Gestational Diabetes Mellitus:current knowledge and unmet needs. J Diabetes. 2016; 8(6): 770-781, doi: 10.1111/1753-0407.12422, indexed in Pubmed: 27121958.

4. Nicholas LM, Morrison JL, Rattanatray L, et al. The early origins of obesity and insulin resistance: timing, programming and mechanisms. Int J Obes (Lond). 2016; 40(2): 229-238, doi: 10.1038/ijo.2015.178, indexed in Pubmed: 26367335.

5. Aubard Y, Darodes N, Cantaloube M. Hyperhomocysteinemia and pregnancy--review of our present understanding and therapeutic implications. Eur J Obstet Gynecol Reprod Biol. 2000; 93(2): 157-165, indexed in Pubmed: 11074137.

6. Walker MC, Smith GN, Perkins SL, et al. Changes in homocysteine levels during normal pregnancy. Am J Obstet Gynecol. 1999; 180(3 Pt 1): 660664, doi: 10.1016/s0002-9378(99)70269-3, indexed in Pubmed: 10076144.

7. Powers RW, Evans RW, Majors AK, et al. Plasma homocysteine concentration is increased in preeclampsia and is associated with evidence of endothelial activation. Am J Obstet Gynecol. 1998; 179(6 Pt 1): 1605-1611, doi: 10.1016/s0002-9378(98)70033-x, indexed in Pubmed: 9855605.

8. Vollset SE, Refsum H, Irgens LM, et al. Plasma total homocysteine, pregnancy complications, and adverse pregnancy outcomes: the Hordaland Homocysteine study. Am J Clin Nutr. 2000; 71(4): 962-968, doi: 10.1093/ajcn/71.4.962, indexed in Pubmed: 10731504.

9. Nelen WL, Blom HJ, Steegers EA, et al. Homocysteine and folate levels as risk factors for recurrent early pregnancy loss. Obstet Gynecol. 2000; 95(4): 519-524, indexed in Pubmed: 10725483.

10. Sukumar N, Rafnsson SB, Kandala NB, et al. Prevalence of vitamin B-12 insufficiency during pregnancy and its effect on offspring birth weight: a systematic review and meta-analysis. Am J Clin Nutr. 2016; 103(5): 12321251, doi: 10.3945/ajcn.115.123083, indexed in Pubmed: 27076577.

11. Yajnik CS, Deshpande SS, Jackson AA, et al. Vitamin B12 and folate concentrations during pregnancy and insulin resistance in the offspring: the Pune Maternal Nutrition Study. Diabetologia. 2008; 51(1): 29-38, doi: 10.1007/s00125-007-0793-y, indexed in Pubmed: 17851649.

12. Knight BA, Shields BM, Brook A, et al. Lower Circulating B12 is Associated with Higher Obesity and Insulin Resistance during Preg- nancy in a Non-Diabetic White British Population. PLoS One. 2015; 10(8): e0135268, doi: 10.1371/journal.pone.0135268, indexed in Pubmed: 26288227.

13. Ghosh S, Sinha JK, Putcha UK, et al. Severe but Not Moderate Vitamin B12 Deficiency Impairs Lipid Profile, Induces Adiposity, and Leads to Adverse Gestational Outcome in Female C57BL/6 Mice. Front Nutr. 2016; 3: 1, doi: 10.3389/fnut.2016.00001, indexed in Pubmed: 26835453.

14. Chango A, Pogribny IP. Considering maternal dietary modulators for epigenetic regulation and programming of the fetal epigenome. Nutrients. 2015; 7(4): 2748-2770, doi: 10.3390/nu7042748, indexed in Pubmed: 25875118.

15. HAPO Collaborative Research Group. Hyperglycemia and adverse pregnancy outcomes. New Eng J Med. 2008; 358: 1991-2002, doi: 10.1056/NEJMoa0707943.

16. Metzger BE, Gabbe SG, Persson B, et al. International Association of Diabetes and Pregnancy Study Groups Consensus Panel. International association of diabetes and pregnancy study groups recommendations on the diagnosis and classification of hyperglycemia in pregnancy. Diabetes Care. 2010; 33(3): 676-682, doi: 10.2337/dc09-1848, indexed in Pubmed: 20190296.

17. Vrachnis N, Augoulea A, lliodromiti Z, et al. Previous gestational diabetes mellitus and markers of cardiovascular risk. Int J Endocrinol. 2012; 2012: 458610, doi: 10.1155/2012/458610, indexed in Pubmed: 22518122

18. Patterson S, Flatt PR, Brennan L, et al. Detrimental actions of metabolic syndrome risk factor, homocysteine, on pancreatic beta-cell glucose metabolism and insulin secretion. J Endocrinol. 2006; 189(2): 301-310, doi: 10.1677/joe.1.06537, indexed in Pubmed: 16648297.

19. Saeed BO, Nixon SJ, White AJ, et al. Fasting homocysteine levels in adults with type 1 diabetes and retinopathy. Clin Chim Acta. 2004; 341(1-2): 27-32, doi: 10.1016/j.cccn.2003.10.034, indexed in Pubmed: 14967155.

20. Gong $T$, Wang J, Yang $M$, et al. Serum homocysteine level and gestational diabetes mellitus: A meta-analysis. J Diabetes Investig. 2016; 7(4): 622-628, doi: 10.1111/jdi.12460, indexed in Pubmed: 27180921.

21. Preedy VRB. Vitamins and Folate: Chemistry, Analysis, Function and Effects. 2nd ed. Royal Society of Chemistry, London 2012.

22. Krishnaveni GV, Hill JC, Veena SR, et al. Low plasma vitamin B12 in pregnancy is associated with gestational, diabesity' and later diabetes. Diabetologia. 2009; 52(11): 2350-2358, doi: 10.1007/s00125-009-1499-0, indexed in Pubmed: 19707742.

23. Lai JS, Pang WW, Cai S, et al. High folate and low vitamin B12 status during pregnancy is associated with gestational diabetes mellitus. Clin Nutr. 2018; 37(3): 940-947, doi: 10.1016/j.clnu.2017.03.022, indexed in Pubmed: 28381340.

24. Seghieri G, Breschi MC, Anichini R, et al. Serum homocysteine levels are increased in women with gestational diabetes mellitus. Metabolism. 2003; 52(6): 720-723, indexed in Pubmed: 12800097.

25. Guven MA, Kilinc M, Batukan C, et al. Elevated second trimester serum homocysteine levels in women with gestational diabetes mellitus. Arch Gynecol Obstet. 2006; 274(6):333-337, doi: 10.1007/s00404-006-0191-6, indexed in Pubmed: 16770586.

26. Idzior-Waluś B, CyganekK, Sztefko K, et al.Total plasma homocysteine correlates in women with gestational diabetes. Arch Gynecol Obstet. 2008; 278(4): 309-313, doi: 10.1007/s00404-008-0571-1, indexed in Pubmed: 18236055.

27. Tarim E, Bagis T, Kilicdag E, et al. Elevated plasma homocysteine levels in gestational diabetes mellitus. Acta Obstet Gynecol Scand. 2004; 83(6): 543-547, doi: 10.1111/j.0001-6349.2004.00540.x, indexed in Pubmed: 15144335 